\title{
Significance of Golgi Protein 73, Alpha-Fetoprotein and Vascular Endothelial Growth Factor Expression in Diagnosis of Primary Hepatic Cancer
}

\author{
Xinfeng Li ${ }^{*}$, Xiaofu Li², Wenrui Zhou1, Gaoxiong Wang1, Wei Wang1 \\ ${ }^{1}$ Department of Hepatobiliary Surgery, Second Affiliated Hospital of Fujian Medical University, \\ Quanzhou, China \\ ${ }^{2}$ Postdoctoral Research Station, Shanghai University of Finance and Economics, Shanghai, China \\ Email: *Surgone-0107@163.com
}

Received 3 October 2015; accepted 30 November 2015; published 3 December 2015

Copyright (C) 2015 by authors and Scientific Research Publishing Inc.

This work is licensed under the Creative Commons Attribution International License (CC BY). http://creativecommons.org/licenses/by/4.0/

\section{(c) (i) Open Access}

\begin{abstract}
Aim: We measured Golgi protein73 (GP73), alpha-fetoprotein (AFP), and vascular endothelial growth factor (VEGF) expression in primary hepatic cancer (PHC) and assessed their clinical significance. Methods: Forty-five PHC and tumor-adjacent specimens and 14 normal liver specimens were examined. GP73, AFP, and VEGF expression was measured via immunohistochemistry and a correlation of protein expression with clinical pathology of PHC was suggested. Results: GP73, AFP, and VEGF expression was significantly higher in PHC and tumor-adjacent tissue compared to tumor-adjacent tissue $(0.143 \pm 0.018$ vs. $0.124 \pm 0.027,0.116 \pm 0.026$ vs. $0.098 \pm 0.014$, and $0.126 \pm$ 0.027 vs. $0.092 \pm 0.016$, respectively; all $p<0.05)$ and normal liver tissue $(0.124 \pm 0.027$ vs. 0.088 $\pm 0.029,0.098 \pm 0.014$ vs. $0.073 \pm 0.011$, and $0.092 \pm 0.016$ vs. $0.076 \pm 0.018$, respectively; all $p<$ 0.05), respectively. GP73 expression was positively correlated with pathological grade and cirrhosis, but not with tumor size, nodules, clinical stage and serum AFP. VEGF expression was positively correlated with tumor size, nodules, portal vein tumor thrombus, and clinical stage, but not with the degree of tumor differentiation and serum AFP. Expression of GP73 and VEGF was greater than that of AFP in PHC (both $p<0.05$ ). Conclusion: GP73 is highly expressed in PHC and may be a diagnostic marker. Combined detection of GP73, AFP, and VEGF is helpful for diagnosis of PHC.
\end{abstract}

\section{Keywords}

Golgi Protein 73, Alpha-Fetoprotein, Vascular Endothelial Growth Factor Expression

\footnotetext{
${ }^{*}$ Corresponding author.
}

How to cite this paper: Li, X.F., Li, X.F., Zhou, W.R., Wang, G.X. and Wang, W. (2015) Significance of Golgi Protein 73, Alpha-Fetoprotein and Vascular Endothelial Growth Factor Expression in Diagnosis of Primary Hepatic Cancer. Journal of Cancer Therapy, 6, 1145-1150. http://dx.doi.org/10.4236/jct.2015.613124 


\section{Introduction}

Primary hepatic cancer (PHC) is a malignant tumor with poor prognosis and rapid progression. Most PHCs are hepatocellular carcinomas (HCC). Using AFP is not ideal method for early PHC diagnosis; a positive serum AFP only occurs $56 \%$ of the time. Fortunately, new tumor markers have been discovered via proteomic techniques and GP73 has been identified to be a novel tumor marker that is related to viral hepatitis and PHC. Research suggests that GP73 expression sensitivity in PHC tissue exceeds AFP and because of this, GP73 may serve as a new oncology index for diagnosing PHC [1]. Here we assess the value of GP73 for diagnosing PHC by measuring this protein in cancer and normal tissue.

\section{Materials and Methods}

We had 45 PHC paraffin specimens (39 HCC; 6 cholangiocellular carcinoma) and 14 cases of normal liver paraffin specimens. These randomly selected samples were obtained from the Second Affiliated Hospital of Fujian Medical University. PHC group patients received no anti-tumor treatment. Table 1 lists patient demographics associated with the samples. All samples were fixed in $100 \mathrm{~g} / \mathrm{L}$ form aldehyde and paraffin-embedded, 4- $\mu \mathrm{m}$ serial sections. Rabbit anti-human GP73 polyclonal antibody was purchased from Abcam (LOCATION). Rat anti-human AFP monoclonal antibody (mAb), ratanti-human VEGF mAb, concentrated SP immunohistochemical staining kits, a DAB chromogenic reagent box, and other supplies were purchased from Beijing Zhongshanjinqiao or Fuzhou Maixin Biotechnology Company (LOCATION).

\subsection{Methods}

Using an immunohistochemical SP method, samples were dewaxed and hydrated and using a high-pressure heating method EDTA antigen retrieval was performed. To the specimens, endogenous peroxidase blockers were added for 10 min. Next, primary antibody was added *MUST STATE DILUTION and was allowed to incubate at $4^{\circ} \mathrm{C}$ overnight. PBS was used to wash the slides and a second generation Immunohistochemical Elivi$\operatorname{sion}^{\mathrm{TM}}$ Plus broad-spectrum kit reagent was used to DO WHAT at room temperature for 20 min. Then, secondary antibody WHAT DILUTION was added after washing at room temperature and incubated for 30 min. PBS was used to wash samples and fresh DAB chromogenic liquid was used for staining. Hematoxylin was added after water washing and samples were viewed under a microscope. Samples for which PBS was used instead of primary antibodies were blank controls.

GP73, AFP, and VEGF are located in cytoplasm and are yellow particles. We chose 5 views of each section and photographed these with an Olympus C7070 with a uniform light source, camera aperture, brightness, contrast, color saturation and with the white balance conditions closed, 400 times view. Image Pro Plus 6.0 was used to analyze photos, measure average photometric absorption values (A values), and take five horizons of the A value for averaging. The A value represents staining intensity, which is correlated to expression [2].

\subsection{Statistical Analysis}

SPSS17.0 software was used for data processing, and data are presented as means \pm SD. A student's t test for means within the groups was used as was single factor ANOVA for mean comparisons among groups. A Pearson correlation co-efficient test for correlation analysis is in double variable measurement data. Significant differences among groups were set at $p<0.05$.

Table 1. Expression of GP73 and VFGF in different tissues (mean \pm sd).

\begin{tabular}{ccc}
\hline Group & mean & VEGF \\
\hline Cancer tissue & GP73 & $0.126 \pm 0.027^{\text {ac }}$ \\
Tumor-adjacent tissue & $0.143 \pm 0.018^{\mathrm{ac}}$ & $0.092 \pm 0.016^{\mathrm{a}}$ \\
Normal tissue & $0.124 \pm 0.027^{\mathrm{a}}$ & $0.076 \pm 0.018$ \\
\hline
\end{tabular}

\footnotetext{
${ }^{\mathrm{a}} p<0.05,{ }^{\mathrm{ac}} p<0.05$.
} 


\section{Results}

GP73 expression measurements in liver cancer, tissue adjacent to cancer tissue and normal liver tissue reveal that GP73 is mainly expressed in the cytoplasm of cancers (Figure 1(A)), as indicated by yellow or yellow-brown particulate staining. Expression in tissue adjacent to carcinoma is visible, but weak compared to carcinoma tissue (Figure 1(B)); Normal liver rarely expresses GP73. A-values for GP73 protein in all tissue types were $0.143 \pm 0.018,0.124 \pm 0.027$, and $0.027 \pm 0.029$ for cancer, adjacent-to-cancer, and normal tissue, respectively. These values were statistically significantly different $(p<0.05)$. GP73 expression was independent of patient age, serum AFP, tumor diameter, and TNM staging, but it was related to pathological Edmondson grading and cirrhosis as depicted in Table 2.

VEGF expression in PHC was found to be chiefly in PHC tissue cell cytoplasm (Figure 2), show yellow or yellow-brown particulate staining. Tissue staining adjacent to carcinomas and normal liver tissue had weaker staining. A-values for VEGF protein in all tissue types were $0.126 \pm 0.027,0.092 \pm 0.016$, and $0.076 \pm 0.018$ for cancer, adjacent-to-cancer, and normal tissue, respectively. These values were statistically significantly different $(p<0.05)$. VEGF expression was greater in tumors larger than $5 \mathrm{~cm}$, in multiple nodules, in tissues with portal vein tumorous thrombosis, and was correlated to TNM staging (III - IV) compared to tumors smaller than $5 \mathrm{~cm}$, single nodules, tissue lacking portal vein tumorous thrombosis, and in tissues TNM-staged I - II.

Table 2. Expression of GP73 in different groups (mean $\pm \mathrm{sd}$ ).

\begin{tabular}{|c|c|c|c|}
\hline Groups & $\mathrm{n}$ & mean & $p$ \\
\hline \multicolumn{4}{|l|}{ Age } \\
\hline$\geq 50$ & 27 & $0.147 \pm 0.017$ & \multirow{2}{*}{$>0.05$} \\
\hline$<50$ & 18 & $0.138 \pm 0.018$ & \\
\hline \multicolumn{4}{|l|}{ Sex } \\
\hline Male & 37 & $0.144 \pm 0.019$ & \multirow{2}{*}{$>0.05$} \\
\hline Female & 8 & $0.140 \pm 0.015$ & \\
\hline \multicolumn{4}{|c|}{ AFP $(\mu \mathrm{g} / \mathrm{L})$} \\
\hline$\geq 400$ & 18 & $0.145 \pm 0.020$ & \multirow{2}{*}{$>0.05$} \\
\hline$<400$ & 27 & $0.142 \pm 0.017$ & \\
\hline \multicolumn{4}{|c|}{ Edmondson } \\
\hline I - II & 34 & $0.138 \pm 0.015$ & \multirow{2}{*}{$<0.05$} \\
\hline III - IV & 11 & $0.161 \pm 0.016$ & \\
\hline \multicolumn{4}{|c|}{ Tumor size (cm) } \\
\hline$\geq 5$ & 25 & $0.145 \pm 0.021$ & \multirow{2}{*}{$>0.05$} \\
\hline$<5$ & 20 & $0.141 \pm 0.015$ & \\
\hline \multicolumn{4}{|l|}{ Node } \\
\hline single & 31 & $0.142 \pm 0.020$ & \multirow{2}{*}{$>0.05$} \\
\hline multiple & 14 & $0.146 \pm 0.013$ & \\
\hline \multicolumn{4}{|l|}{ TNM } \\
\hline I-II & 25 & $0.143 \pm 0.012$ & \multirow{2}{*}{$>0.05$} \\
\hline III-IV & 20 & $0.144 \pm 0.019$ & \\
\hline \multicolumn{4}{|l|}{ cirrhosis } \\
\hline & 22 & $0.149 \pm 0.015$ & \multirow{2}{*}{$>0.05$} \\
\hline & 23 & $0.135 \pm 0.018$ & \\
\hline
\end{tabular}



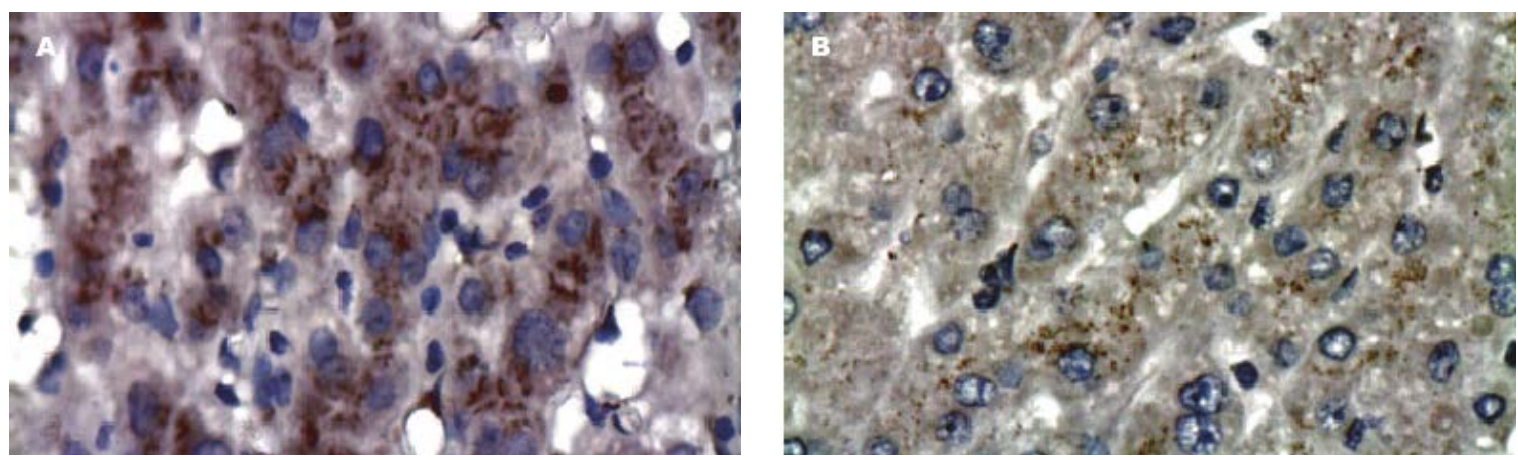

Figure 1. Expression of GP73 in liver tissue (Elivision ${ }^{\mathrm{TM}}$ Plus two steps $\times 400$ ). (A) Cancer tissue; (B) Tumor-adjacent tissue.

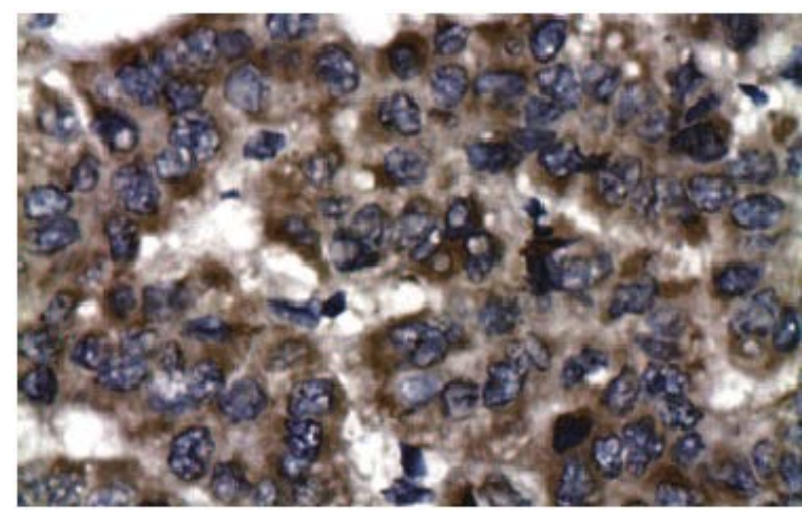

Figure 2. Expression of VEGF in liver tissue (Elivision ${ }^{\mathrm{TM}}$ Plus two steps $\left.\times 400\right)$.

To study the relationship among GP73, AFP, and VEGF expression patterns in liver tissue, we compared expression patterns of each protein. GP73 and VEGF expressed in PHC were greater than AFP in carcinoma tissue ( $0.148 \pm 0.018$ vs. $0.116 \pm 0.026,0.126 \pm 0.027$ vs. $0.116 \pm 0.026, p<0.05)$. AFP expression was different, comparing adjacent tissue to carcinoma tissue and normal tissue $(0.098 \pm 0.014$ vs. $0.073 \pm 0.011, p<0.05)$. GP73 and VEGF expression in PHC were positively correlated ( $r=0.298, p<0.05)$. The A-values of GP73 of 30 HCC cases and 6 cholangiocellular carcinoma samples were not statistically significant different $(0.143 \pm$ 0.018 vs. $0.144 \pm 0.012, p<0.05$ ).

\section{Discussion}

In the field of proteomics, tumors are considered protein-deficiency diseases and proteins are known to change of the course of early tumor stages. GP73 is a Golgi II transmembrane protein, with a terminal amino acid that can be easily converted to an N-glycan. GP73 is chiefly expressed in multiple human epithelial cell tissues, is increased in viral hepatic cells, and is rarely expressed in normal tissue. Block's group reported that serum GP73 was increased in a marmot liver cancer model [3]. Marrero and co-workers measured serum protein in 352 specimens using Western blot, and confirmed that serum GP73 in HCC patients is significantly higher than in individuals with cirrhosis, and that the sensitivity for the early HCC detection was superior to AFP. Thus, GP73 is a potential biomarker for diagnosing HCC [1].

Recently, a Golgi membrane protein similar to GP73 with an N-or C-end anchor have been described (Golgin-84, P63, Gpp130, etc.). Common to each is an N-or C-side spiral structure, but the biochemical function of these proteins is uncertain. On study suggested that P63 increased when liver cells were shocked. This was interpreted to mean that the function of P63 may be associated with the cellular stress response, and the spiral structure, which is a homologous protein interaction site, may be associated with adhesion, combination, and transfer of the transfer bubble and transport protein [4]. Studies in knockout HepG2.2.15 cells indicated that GP73 expression changes are related to a decreased Golgi complex surface area. GP73 expression may be asso- 
ciated with structural integrity maintenance of the Golgi apparatus, and organelle integrity is related to human cancer, specifically nuclear damage and mitochondrial perturbations, as it allow cancer cells to adapt to cancer cell metabolic demands [5]. Also, studies of the role of the Golgi apparatus in protein secretion, such as changes in composition related to tumor development confirmed that this organelle may be a tumor biomarker. A Golgi membrane protein has been identified in tumors; specifically, GP73 was confirmed to be upregulated in PHC. However, the secretion, transportation, and specific biochemical function of GP73 is uncertain. Studies suggest that upregulated GP73 may be due to triggered acute hepatocellular injury and chronic tissue remodeling and fibrogenesis [6].

The tumor growth largely depends on angiogenesis. Tumor cells, during proliferation and infiltration, release angiogenic factors to induce vessel formation and these new vessels are weak with abnormal shapes, allowing tumor invasion. The glycoprotein VEGF is an angiogenic factor (34 - $46 \mathrm{kDa}$ ) that is expressed in normal blood vessel generation during bone growth and embryogenesis; Upregulated VEGF in tumor tissues and cells and inflammatory cells (macrophages, mast cells) within tumors stimulates tumor vascular endothelial cells and promotes proliferation, migration, and angiogenesis to support tumor growth, increased blood vessel permeability, fibrous protein formation and the formation of blood vessel stroma. All of these events contribute to tumor metastases. VEGF combined with VEGFR is necessary for angiogenesis and induce endothelial cell proliferation and tube formation. Liver cancer is rich with blood vessels and VEGF mRNA and protein are highly expressed in this type of cancer [7]. At every stage of development of hepatocellular carcinoma, active proliferation of endothelial cells occurs and VEGFR expression on cell surfaces is increased. The angiogenesis is important for carcinoma tissue biological invasion of tumor.

AFP is a glycogen protein synthesized in hepatic and yolk sac cells. Some AFP arises from gastrointestinal mucosa cells from the endoderm. After birth, AFP is rapidly reduced and replaced with albumin. Adult livers contain pluripotent stem cells that will differentiate into hepatocytes and bile duct cells. Oval cells are thought to be descendants of hepatic stem cells with the capacity to synthesize AFP and develop into tumors. These hepatic stem cells are considered to be an origin of AFP-producing HCC [8]. The diagnostic value of increased AFP for liver cancer was established nearly 40 years ago. AFP specificity is only not superior to pathologic examination but it has a false positive rate of $\sim 2 \%$ for early diagnosis. One limitation of AFP is that $\sim 30 \%$ of PHCs are AFP-negative and this may be explained by the idea that AFP is synthesized in a specific phase of the cell cycle and HCC has two cell types. Also, during the cell cycle, liver cancer cells can store AFP when the AFP gene is stimulated by low methylation. Therefore, AFP may be a specific marker for liver cancer diagnosis. If AFP gene expression regulation stops between transcription and translation, serum AFP does not necessarily indicate an absence of liver cancer and this restricts the value of this marker.

\section{Conclusion}

We conclude that GP73, AFP, and VEGF expression in liver cancer is significantly greater than this expression in normal tissue and as such, it may be exploited for diagnosing PHC. GP73 expression is not related to tumor size or differentiation, clinical staging, and serum AFP. GP73 expression is associated with VEGF expression in liver cancer and GP73 stimulates angiogenesis under hypoxia and this prevents apoptosis. Joint detection of all three proteins may help diagnose PHC, especially for patients with AFP-negative cancers.

\section{Disclaimers}

No conflicts.

\section{Source of Support}

The item of Fujian Provincial Health Department: Number: 2012-CXB-22.

\section{References}

[1] Marrero, J.A., Romano, P.R., Nikolaeva, O., Steel, L., Mehta, A., Fimmel, C.J., Comunale, M.A., D’Amelio, A., Lok, A.S. and Block, T.M. (2005) GP73, a Resident Golgi Glycoprotein, Is a Novel Serum Marker for Hepatocellular Carcinoma. Journal of Hepatology, 43, 1007-1012. http://dx.doi.org/10.1016/j.jhep.2005.05.028

[2] Shen, H. (1995) Quantitative Methods of Immunohistochemical Staining (III). Chinese Journal of Histochemistry and 
Cytochemistry, 4, 89-91.

[3] Block, T.M., Comunale, M.A., Lowman, M., Steel, L.F., Romano, P.R., Fimmel, C., Tennant, B.C., London, W.T., Evans, A.A, Blumberg, B.S., Dwek, R.A., Mattu, T.S. and Mehta, A.S. (2005) Use of Targeted Glycoproteomics to Identify Serum Glycoproteins that Correlate with Liver Cancer in Woodchucks and Humans. Proceedings of the National Academy of Sciences of the United States of America, 102, 779-784. http://dx.doi.org/10.1073/pnas.0408928102

[4] Kladney, R.D., Cui, X., Bulla, G.A, Brunt, E.M. and Fimmel, C.J. (2002) Expression of GP73, a Resident Golgi Membrane Protein, in Viral and Nonviral Liver Disease. Hepatology, 35, 1431-1440. http://dx.doi.org/10.1053/jhep.2002.32525

[5] Wei, S., Dunn, T.A., Isaacs, W.B., De Marzo, A.M. and Luo, J. (2008) GOLPH2 and MYO6: Putative Prostate Cancer Markers Localized to the Golgi Apparatus. Prostate, 68, 1387-1395. http://dx.doi.org/10.1002/pros.20806

[6] Iftikhar, R., Kladney, R.D., Havlioglu, N., Schmitt Graff, A., Gusmirovic, I., Solomon, H., Luxon, B.A., Bacon, B.R. and Fimmel, C.J. (2004) Disease and Cell-Specific Expression of GP73 in Human Liver Disease. The American Journal of Gastroenterology, 99, 1087-1095. http://dx.doi.org/10.1111/j.1572-0241.2004.30572.x

[7] Poon, R.T., Lau, C., Pang, R., Ng, K.K., Yuen, J. and Fan, S.T. () High Serum Vascular Endothelial Growth Factor Levels Predict Poor Prognosis after Radiofrequency Ablation of Hepatocellular Carcinoma: Importance of Tumor Biomarker in Ablative Therapies. Annals of Surgical Oncology, 14, 1835-1845. http://dx.doi.org/10.1245/s10434-007-9366-z

[8] Kawarai, S., Hashizaki, K., Kitao, S., Nagano, S., Madarame, H., Neo, S., Ishikawa, T., Furuichi, M., Hisasue, M., Tsuchiya, R., Tsujimoto, H. and Yamada, T. (2006) Establishment and Characterization of Primary Canine Hepatocellular Carcinoma Cell Lines Producing Alpha-Fetoprotein. Veterinary Immunology and Immunopathology, 113, 30-36. http://dx.doi.org/10.1016/j.vetimm.2006.03.006 